\title{
Benchmarking Biological Nutrient Removal in Wastewater Treatment Plants Influence of Mathematical Model Assumptions
}

Flores-Alsina, Xavier; Gernaey, Krist; Jeppsson, Ulf

Published in:

8th IWA Symposium on Systems Analysis and Integrated Assessment

Publication date:

2011

Document Version

Publisher's PDF, also known as Version of record

Link back to DTU Orbit

Citation (APA):

Flores-Alsina, X., Gernaey, K., \& Jeppsson, U. (2011). Benchmarking Biological Nutrient Removal in Wastewater Treatment Plants: Influence of Mathematical Model Assumptions. In 8th IWA Symposium on Systems Analysis and Integrated Assessment (pp. 640-647)

\section{General rights}

Copyright and moral rights for the publications made accessible in the public portal are retained by the authors and/or other copyright owners and it is a condition of accessing publications that users recognise and abide by the legal requirements associated with these rights.

- Users may download and print one copy of any publication from the public portal for the purpose of private study or research.

- You may not further distribute the material or use it for any profit-making activity or commercial gain

- You may freely distribute the URL identifying the publication in the public portal 


\title{
Benchmarking Biological Nutrient Removal in Wastewater Treatment Plants: Influence of Mathematical Model Assumptions
}

\author{
Xavier Flores-Alsina ${ }^{1}$, Krist V. Gernaey ${ }^{2}$ and Ulf Jeppsson ${ }^{1}$ \\ ${ }^{1}$ Division of Industrial Electrical Engineering and Automation (IEA), Department of Measurement \\ Technology and Industrial Electrical Engineering (MIE), Lund University, Box 118, SE-221 00 \\ Lund, Sweden. E-mail : \{xavier.flores, ulf.jeppsson $\} @$ iea.lth.se. \\ ${ }^{2}$ Center for Process Engineering and Technology (PROCESS), Department of Chemical and \\ Biochemical Engineering, Technical University of Denmark, Building 229, DK-2800 Kgs. \\ Lyngby, Denmark. E-mail: kvg@kt.dtu.dk
}

\begin{abstract}
This paper examines the effect of different model assumptions when describing biological nutrient removal (BNR) by the activated sludge models (ASM) $1,2 \mathrm{~d} \& 3$. The performance of a nitrogen removal $(W W T P 1)$ and a combined nitrogen and phosphorus removal (WWTP2) benchmark wastewater treatment plant was compared for a series of model assumptions. Three different model approaches describing BNR are considered. In the reference case, the original model implementations are used to simulate WWTP1 (ASM1 \& 3) and WWTP2 (ASM2d). The second set of models includes a reactive settler, which extends the description of the nonreactive TSS sedimentation and transport in the reference case with the full set of ASM processes. Finally, the third set of models is based on including electron acceptor dependency of biomass decay rates for ASM1 (WWTP1) and ASM2d (WWTP2). The results show that incorporation of a reactive settler: 1) increases the hydrolysis of particulates; 2) reduces the $S_{\mathrm{NO} 3}$ concentration (bottom of clarifier); 3 ) increases the oxidation of COD compounds; 4) increases $X_{\mathrm{B}}$ and $X_{\mathrm{A}}$ decay; and, finally, 5) increases the growth of $X_{\mathrm{PAO}}$ and formation of $X_{\mathrm{PHA}}$ for ASM2d. Introduction of electron acceptor dependent decay leads to a substantial increase of the concentration of $X_{\mathrm{A}}, X_{\mathrm{B}}$ and $X_{\mathrm{PAO}}$ in the bottom of the clarifier. The paper ends with a critical discussion of the influence of the different model assumptions, and emphasizes the need for a model user to understand the significant differences in simulation results that are obtained when applying different combinations of 'standard' models.
\end{abstract}

Keywords: ASM1, ASM2d, ASM3, Activated Sludge Model, benchmarking, electron-acceptor dependent decay, reactive settler

\section{INTRODUCTION}

Activated Sludge Models (ASMs) are widely used for benchmarking (Copp, 2002; Jeppsson et al., 2007), diagnosis (Rodriguez-Roda et al., 2002), design (Flores et al., 2007), teaching (Hug et al., 2009) and optimization (Rivas et al., 2008) of wastewater treatment plants (WWTPs). The ASM family (Henze et al., 2000) successfully describes the biochemical removal of organic carbon (C), nitrogen $(\mathrm{N})$ and phosphorus $(\mathrm{P})$ and can be considered as reference models, since these models triggered the general acceptance of WWTP modeling, first in the research community and later on also in engineering consultancy.

Continuous research is still carried out in order to extend these models, for example by including additional processes, with the purpose of improving biological nutrient removal (BNR) predictions. Some of these recent developments are: $\mathrm{pH}$ calculation (Serralta et al., 2004), two step nitrification-denitrification (Sin et al., 2008), four step denitrification (Hiatt and Grady, 2008), the inclusion of toxic compounds (Copp and Spanjers, 2004) and the effect of microbiology-related TSS separation problems (Flores-Alsina et al., 2009.). However, thus far the implications of different model assumptions resulting in changes in the model structure have not been thoroughly compared in the three most widespread ASM implementations, i.e. ASM1, 2d and 3. 
The Benchmark Simulation Model (BSM) platform has been widely used in both academia and industry for unbiased comparison of control strategies (Copp, 2002). The original activated sludge configuration of the BSM1 has for example been upgraded for other plant configurations (Gernaey and Jørgensen, 2004). In addition, the BSM1 was adapted for long-term evaluation (Rosen et al., 2004), and has been extended with additional units, resulting in a plant-wide simulation benchmark, the BSM2 (Jeppsson et al., 2007; Nopens et al., 2010). In this manuscript, the BSM platform was used to examine the effects of different model assumptions when describing the BNR processes considered by the ASM1, $2 \mathrm{~d} \& 3$. The differences when adding a reactive settler and electrodependent decay rates to the original ASM implementations are compared using two benchmark WWTPs. The simulation results are complemented with a rigorous analysis of soluble and particulate compounds in both the sludge blanket and the effluent. The paper is organized as follows: First, the two benchmark WWTP designs and operational conditions are presented. Next, the investigated set of different modeling approaches is described. Finally, conclusions are drawn with a critical discussion of the results.

\section{METHODS}

\subsection{WASTEWATER TREATMENT PLANTS UNDER STUDY}

Two benchmark wastewater treatment plants are considered in this study. First, a $\mathrm{N}$ removal plant (WWTP1) consisting of five reactors in series and one sedimentation tank (SEC) is investigated. Tanks 1 and 2 are anoxic (ANOX1,2) while 3, 4 and 5 are aerobic (AER1, 2 and 3). AER3 and ANOX1 are linked by means of an internal recycle $\left(Q_{\text {intr }}\right)$. A default open loop control strategy is defined based on the following values: $\mathrm{K}_{\mathrm{L}}$ a (AER1, $2 \& 3$ ) $=240,240$ and 84 day $^{-1}$ (aeration intensity, represented as the volumetric oxygen transfer coefficient), $\mathrm{Q}_{\mathrm{r}}=18446 \mathrm{~m}^{3}$ day $^{-1}$ (external recirculation) and $\mathrm{Q}_{\mathrm{w}}=385 \mathrm{~m}^{3}$ day $^{-1}$ (wastage flow rate). Further information about design and operational characteristics can be found in Copp (2002). Secondly, a combined N and phosphorus (P) removal plant $(W W T P 2)$ is studied, where two additional anaerobic reactors (ANAER1, 2) with a total volume of $2000 \mathrm{~m}^{3}$ are added in front of WWTP1. This plant has the same operational characteristics as WWTP1.

\subsection{MATHEMATICAL MODELS}

Three sets of model assumptions describing BNR processes are compared:.

- In the reference case, the ASM1 and ASM3 (Henze et al., 2000) are chosen to describe the biological processes in WWTP1, while for WWTP2 the selected model is the ASM2d (Henze et al., 2000). In all cases the double exponential velocity function of Takács et al. (1991) is used to model the secondary settling process through a one-dimensional non-reactive 10-layer settler.

- The second set of models is an extension of the reference case, upgrading the description of the TSS sedimentation and transport in the settler with the full set of ASM1, ASM3 (WWTP1) and ASM2d (WWTP2) equations, i.e. introducing reactive settlers.

- Finally, the third set of models is based on extending ASM1 (WWTP1) and ASM2d (WWTP2) with biomass decay rates that are electron acceptor dependent (Germaey and Jørgensen, 2004). In this case, ASM3 (WWTP1) is not modified because it already includes the possibility to differentiate the decay rates of heterotrophs and autotrophs in aerobic and anoxic conditions.

An influent profile was generated following the principles outlined in Gernaey et al. (2011). All plant models are subjected to identical influent flow rate and pollutant loads in terms of COD and N (P added to WWTP2 input as well). Simulation results were evaluated dynamically during the last seven days of simulation in accordance to BSM1 principles (100 days simulation to reach steady state, then 28 days of dynamic influent data, only the last seven days are used for evaluation). 


\section{BNR PERFORMANCE WITH REACTIVE SETTLER (ASM1, 2d and 3) \\ 3.1. SECONDARY SETTLER DYNAMIC RESULTS}

When ASM1, 2d and 3 processes are implemented in the secondary settler model (model assumption set number two), there are substantial differences in the behaviour of the soluble components $(S)$. The $S_{\mathrm{O} 2}$ concentration decreases rapidly towards the bottom of the clarifier, thus increasing the overall denitrification efficiency, i.e. the $S_{\mathrm{NO} 3}$ concentration is reduced using $S_{\mathrm{S}}$ as substrate (see $S_{\mathrm{O} 2}, S_{\mathrm{NO} 3}$ and $S_{\mathrm{S}}$ profiles in Figure 1). Figure 1 also shows a slight increase of the underflow concentrations of $S_{\mathrm{NH}}$ and $S_{\mathrm{PO} 4}$, mainly due to increased hydrolysis ( $S_{\mathrm{PO} 4}$ just in ASM2d). The fate of the particulate $X_{\mathrm{S}}, X_{\mathrm{I}}, X_{\mathrm{H}}, X_{\mathrm{A}}$ and $X_{\mathrm{PAO}}$ components in the settler was also investigated. In both WWTP1 and 2, the $X_{\mathrm{S}}$ fraction is higher at the feed point and decreases both towards the top and the bottom of the clarifier as a result of hydrolysis. Moreover, $X_{\mathrm{B}}$ and $X_{\mathrm{A}}$ concentrations decrease at the bottom of the clarifier due to a higher decay rate thereby resulting in an increase of $X_{\mathrm{I}}$ (see Figure 2). Finally, for ASM2d (WWTP2), it can be observed that the $X_{\text {PAO }}$ concentration is dramatically increased (Figure 2). This is mainly due to the lower quantity of $S_{\mathrm{NO} 3}$ returned via the internal recycle flow to ANAER1. Thus, there is a less pronounced inhibition of the $\mathrm{P}$ release process, because the readily biodegradable substrates $\left(S_{\mathrm{A}}\right.$ and $\left.S_{\mathrm{F}}\right)$ entering the WWTP are now increasingly used to create cell internal $X_{\mathrm{PHA}}$ (the concentration of this component also increases) instead of using $S_{\mathrm{NO} 3}$ as electron acceptor.

\subsection{EFFLUENT DYNAMIC RESULTS}

Compared to the reference case, the simulation results show that there is an increase of the effluent $S_{\mathrm{NH}}$ concentration in both ASM1 (WWTP1) and ASM2d (WWTP2) reactive settler implementations (Figure 3). This fact is attributed to the introduction of autotrophic decay in the lower layers of the settler, i.e. $X_{\mathrm{A}}$ biomass dies and does not grow due to the anoxic conditions at the bottom of the secondary settler. This is also closely related to the lower effluent $S_{\mathrm{NO} 3}$ concentration. Most probably it is caused by: 1) lower $S_{\mathrm{NO}}$ production in AER due to reduced nitrification efficiency; and, 2) the additional anoxic zone in SEC with resulting higher denitrification rates. However, ASM3 (WWTP1) presents a competently different behaviour. There, a decrease of $S_{\mathrm{NH}}$ concentration is observed because of: 1) a lower decay rate due to its electron acceptor dependency in the mathematical representation of ASM3; and 2) a limited additional nitrification volume in the aerobic section of the settler (top). $S_{\mathrm{NO} 3}$ also decreases (like in ASM1 and 2d) due to the additional anoxic zone in the bottom part of SEC. Finally, in the ASM2d implementation (WWTP2), the higher $X_{\mathrm{PAO}}$ and $X_{\mathrm{PHA}}$ concentrations achieved in ANAER with the reactive settler, increase the overall $\mathrm{P}$ uptake efficiency in both ANOX and AER zones. Hence, when a reactive settler is introduced, there is a lower $S_{\mathrm{PO} 4}$ concentration in the effluent (see $\mathrm{P}$ profile in Figure 3).

\section{BNR PERFORMANCE WITH REACTIVE SETTLER AND DECAY MODIFICATION (ASM1 and 2d)}

\subsection{SECONDARY SETTLER DYNAMIC RESULTS}

There are no substantial variations regarding the underflow concentrations of $S_{\mathrm{O}}, S_{\mathrm{NH}}, S_{\mathrm{NOX}}$ and $S_{\mathrm{PO} 4}$ with respect to the previous approach. The soluble components follow the same dynamics (see Figure 1). Nevertheless, some interesting changes can be observed in the biomass. The reduced decay rates in this third set of models increase the $X_{\mathrm{B}}, X_{\mathrm{A}}$ and $X_{\mathrm{PAO}}$ (and consequently a reduced $X_{\mathrm{I}}$ ) concentrations at the bottom of SEC (even reaching higher concentrations than in the default case) (see in Figure 1 the $X_{\mathrm{I}}, X_{\mathrm{S}}, X_{\mathrm{B}}, X_{\mathrm{A}}$ and $X_{\mathrm{PAO}}$ profiles). The reason for this behaviour is the deathregeneration principle, where the decay of biomass in ASM1 and ASM2d leads to generation of new substrate $\left(X_{\mathrm{S}}\right)$ (although the remaining $X_{\mathrm{S}}$ is always lower because it is rapidly hydrolyzed). In ASM3, the death re-generation principle is no longer present, and thus the effect of the decay process on the biomass resulting from a reactive settler model is different. 


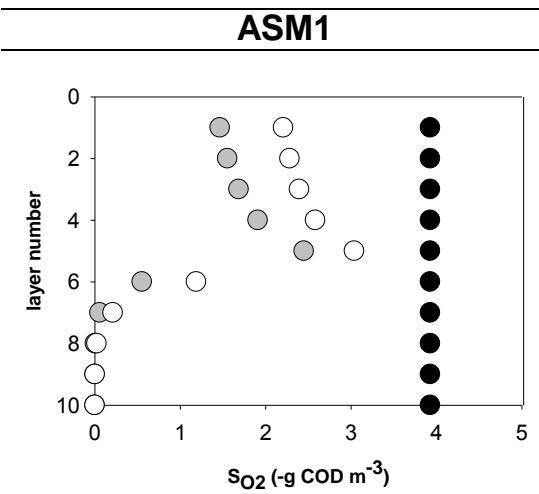

ASM2d

ASM3
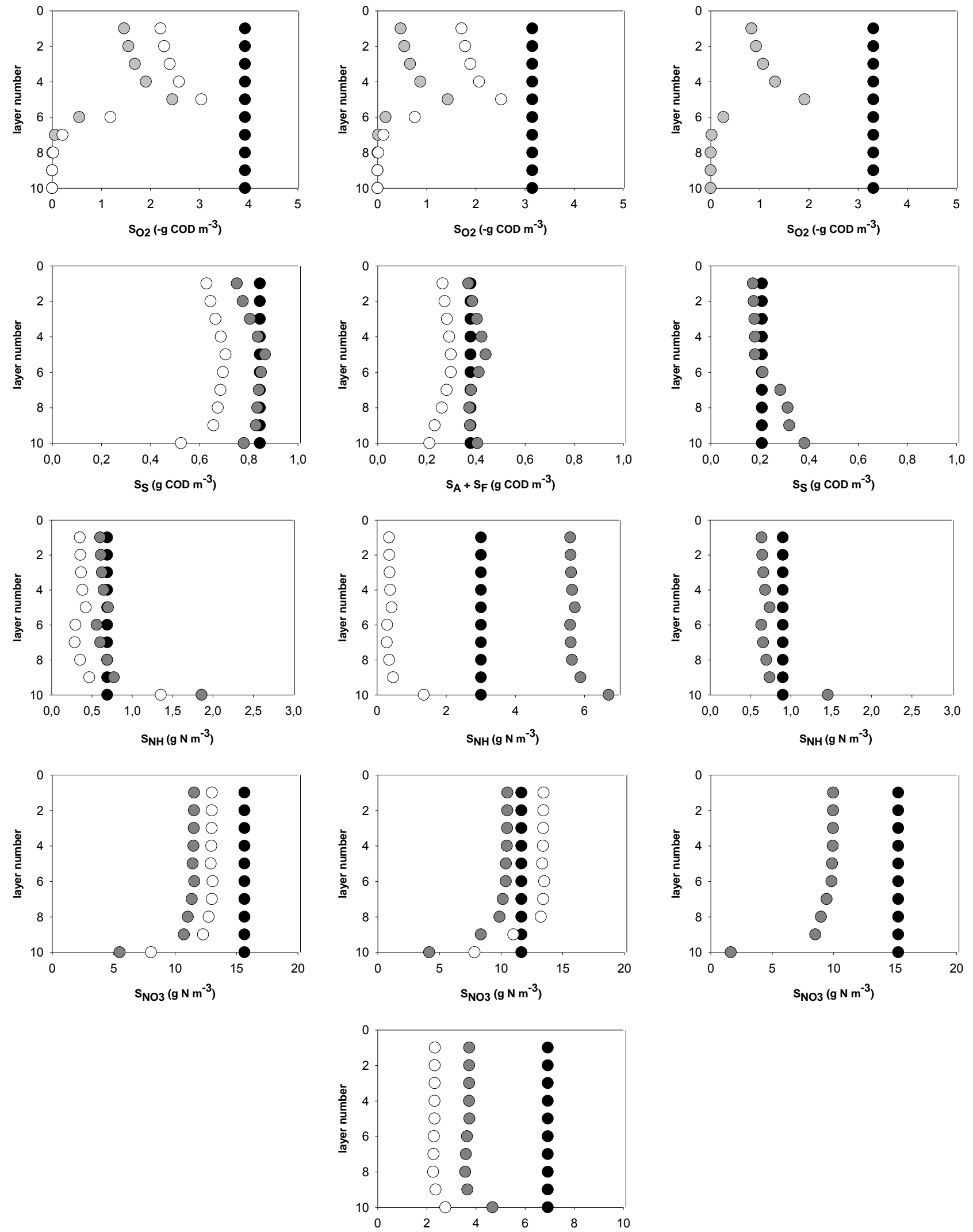

$\mathrm{SPO}\left(\mathrm{g} \mathrm{P} \mathrm{m}^{-3}\right)$

Figure 1. $S_{\mathrm{O} 2}$ (first row), $\mathrm{S}_{\mathrm{S}}$ (second row), $S_{\mathrm{NH}}$ (third row), $S_{\mathrm{NO} 3}$ (fourth row) and $S_{\mathrm{PO} 4}$ (fifth row) concentrations in the different layers of the settler at stady state for ASM1 (first column), ASM2d (second column) and ASM3 (third column). The different modelling concepts are colour coded: black (default), grey (reactive settler) and white (reactive settler + decay modification) 


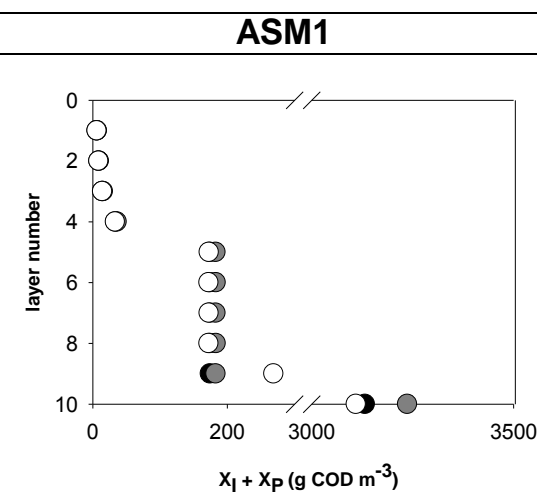

ASM2d

ASM3
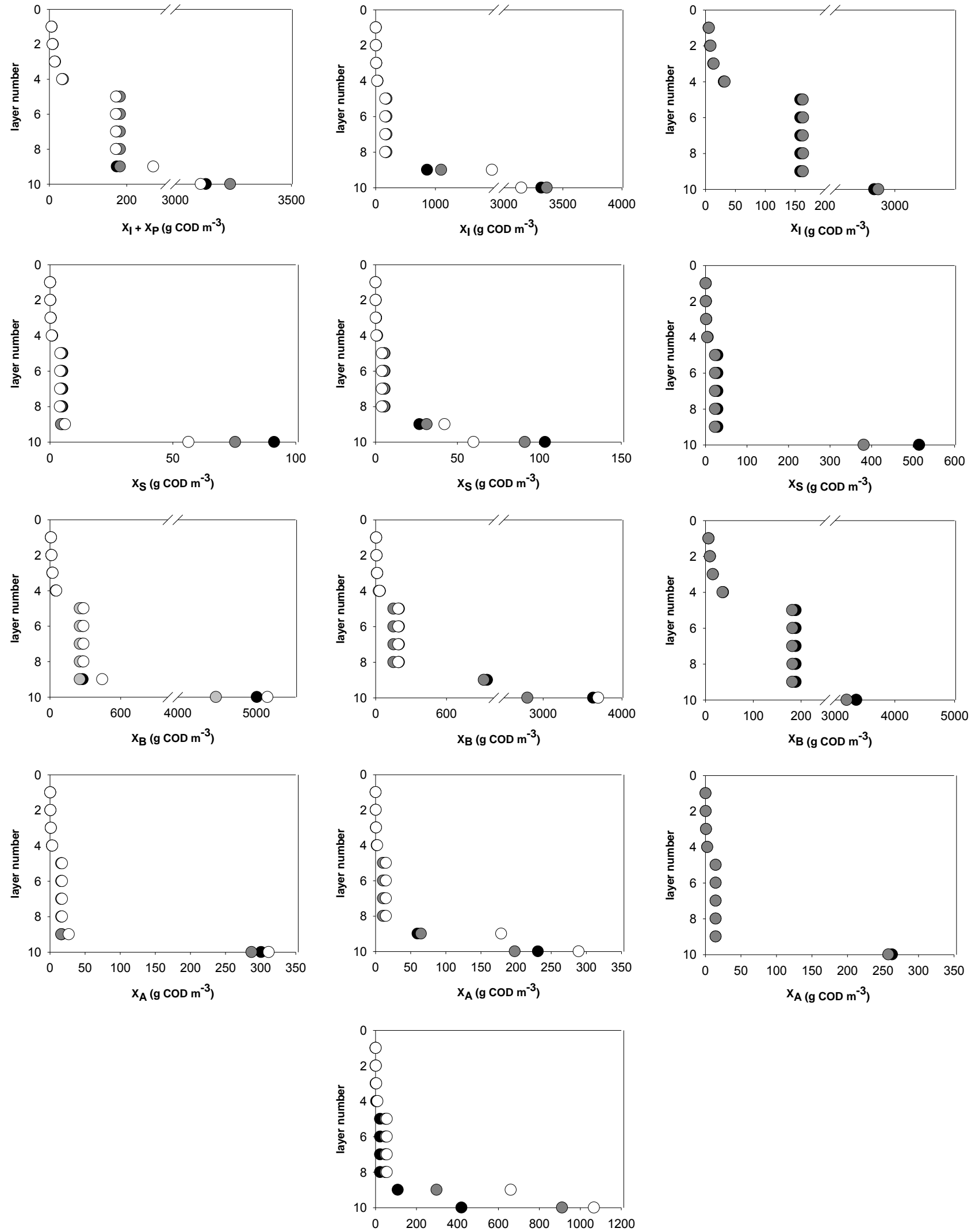

$X_{P A O}\left(g\right.$ COD $\left.m^{-3}\right)$

Figure 2. $X_{\mathrm{i}}$ (first row), $X_{\mathrm{S}}$ (second row), $X_{\mathrm{H}}$ (third row), $X_{\mathrm{A}}$ (fourth row) and $X_{\mathrm{PAO}}$ (fifth row) concentrations in the different layers of the settler at steady state. for ASM1 (first column), ASM2d (second column) and ASM3 (third column). The different modelling concepts are colour coded: black (default), grey (reactive settler) and white (reactive settler + decay modification) 


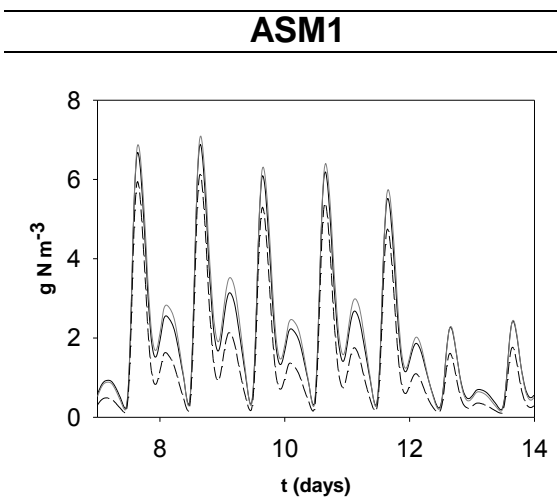

ASM2d
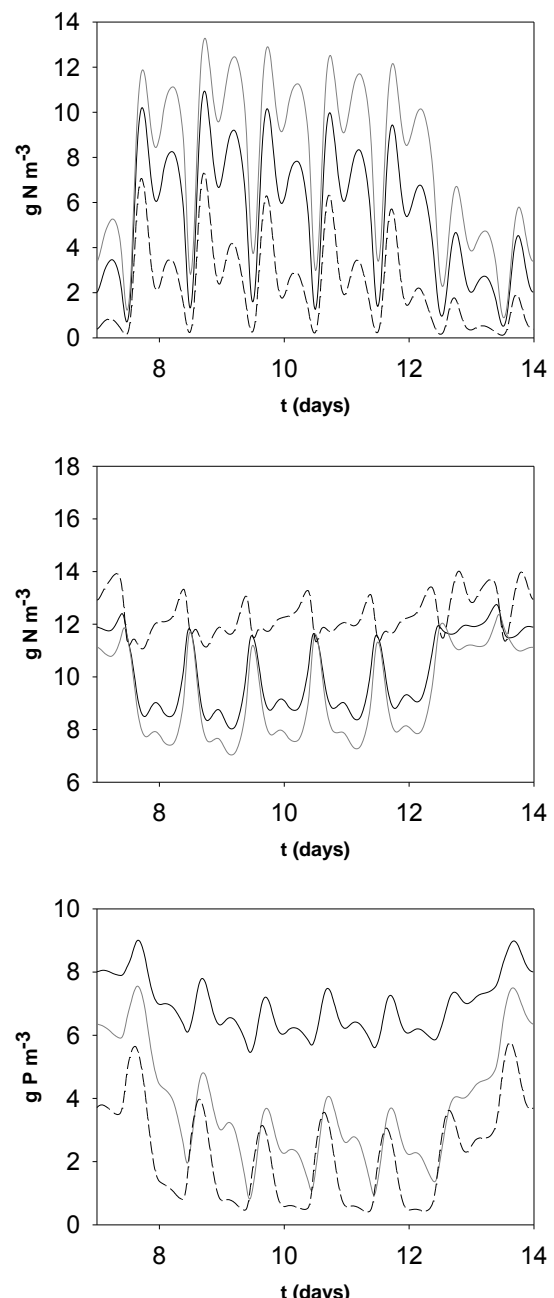

ASM3
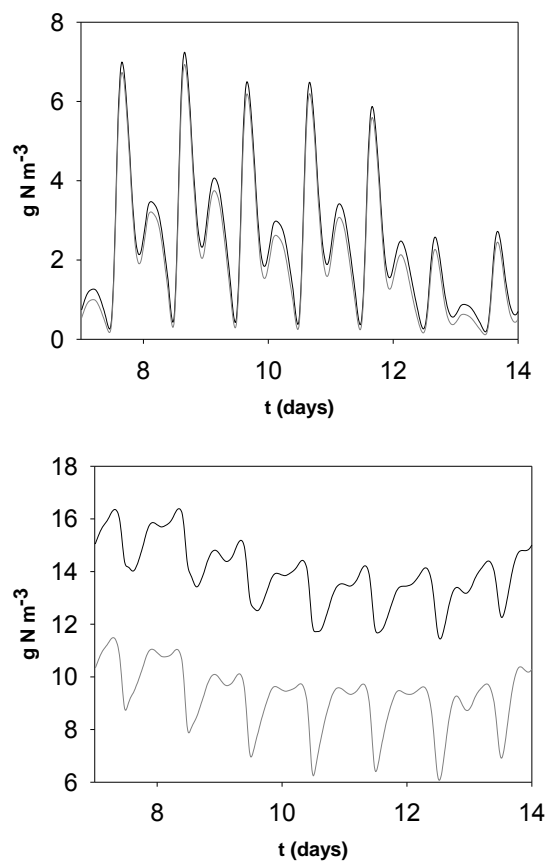

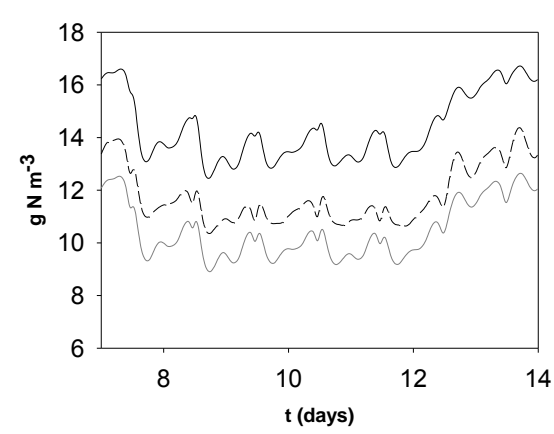

Figure 3. $S_{\mathrm{NH}}$ (first row), $S_{\mathrm{NO}}$ (second row) and $S_{\mathrm{PO} 4}$ (third row) effluent dynamic profiles for ASM1 (first column), ASM2d (second column) and ASM3 (third column). The different modelling concepts are colour coded: black (default), grey (reactive settler) and dashed (reactive settler + decay rate modification).

\subsection{EFFLUENT DYNAMIC RESULTS}

Introduction of electron-acceptor dependent decay rates in the models generally increases the overall BNR efficiency when compared to a stand-alone reactive settler implementation. $S_{\mathrm{NH} 4}$ and $S_{\mathrm{PO} 4}$ concentrations are lower since reduced decay under anoxic (ASM1, ASM2d) and anaerobic (ASM2d) conditions will result in increased $X_{\mathrm{A}}$ and $X_{\mathrm{PAO}}$ concentrations for the same sludge wastage flow rate (see Figure 3). In the ASM2d implementation, $S_{\text {NOX }}$ increases slightly for two reasons: 1) higher nitrification efficiency, i.e. more nitrate production and 2) improved $S_{\mathrm{A}}$ uptake by

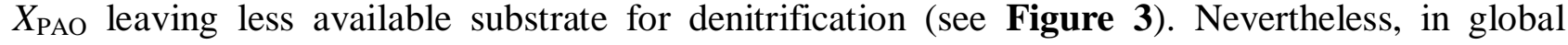
terms, it can be said that the total $\mathrm{N}$ and total $\mathrm{P}$ are lower in the effluent as a consequence of the extra reactive volume in the secondary settler and a better description of the biomass behaviour in the anaerobic, anoxic and aerobic biological reactors.

\section{DISCUSSION}

The results reported in this paper need a thorough discussion. An important observation is that the representation of decay rates in the original ASM1 and 2d implementations, more specifically the absence of electron-acceptor dependency, makes those models less suitable to simulate BNR in WWTP 1 and 2 in case a reactive settler is used. According to experimental observations reported in Siegrist et al. (1999), there is a differentiation (in decay rate) amongst aerobic, anoxic and anaerobic conditions. The overprediction of the effect of decay is especially critical in the ASM2d 
case, where an approximate increase in the effluent $S_{\mathrm{NH}}$ of about $50 \%$ can be observed as a consequence of introducing a reactive settler with standard ASM2d reactions added to the settler model. The efficiency of the simulated $\mathrm{N}$ removal processes improves significantly by including a more realistic assumption that decay process rates are electron-acceptor dependent.

Another important observation relates to the denitrification in the secondary settler. In the three reactive settler implementations (ASM1, 2d \&3) one can observe: 1) reduction of $\mathrm{S}_{\mathrm{O} 2}$ and 2) increase of the $X_{S}$ hydrolysis rate, which can promote a substantial removal of $\mathrm{S}_{\mathrm{NO} 3}$ in the lower layers of the secondary settler (high biomass concentration). The consideration of these processes is extremely important because the whole denitrification potential of the WWTP might be underestimated if using a standard non-reactive settler model. Closely related to this phenomenon, the potential appearance of rising sludge should be mentioned. Rising sludge is characterized by appearance of rising or floating activated sludge flocs with poor settling characteristics in a relatively short period of time. The main reason for rising sludge is the conversion of nitrate to nitrogen gas. If enough gas is formed, the sludge mass becomes buoyant and rises or floats to the surface worsening the clarification efficiency. Comas et al. (2008) pointed out the importance of also considering microbiology related TSS separation problems during simulation studies. Rising sludge is not currently included in the available settling models, but with the reactive settler approach presented in this paper, an additional floating process could be included in order to predict also these (undesirable) episodes.

The $S_{\mathrm{NO}}$ plays an important role during biological P removal. More specifically, the presence of $S_{\mathrm{NO} 3}$ has a tremendous impact on the $\mathrm{P}$ accumulating population. A model based on a non-reactive settler overestimates the quantity of retuned $S_{\mathrm{NO} 3}$ via external recirculation. Both $X_{\mathrm{B}}$ and $X_{\mathrm{PAO}}$ use the very same substrate, but heterotrophs $\left(X_{\mathrm{B}}\right)$ have a competitive advantage due to their faster growth kinetics. This also implies that a secondary settler with high retention time could be considered as an alternative denitification zone. Since P uptake processes in ASM2d are extremely sensitive to $S_{\mathrm{NO} 3}$ presence, a non-reactive settler can predict unrealistic P removal efficiencies. Again, it is important to point out the importance of considering electron-acceptor dependent decay rates when a reactive settler is used. Lower decay rates for $\mathrm{X}_{\mathrm{PAO}}$ are expected under anoxic and anaerobic conditions.

Finally, the importance of the WWTP model purpose or the model study objectives needs to be mentioned, since it will greatly influence the ASM selection. Assume a modelling study, where the aerobic/anoxic zones need to be refined from the results obtained by a design guideline, e.g. Metcalf \& Eddy. In that case, ASM1 (only N) and 2d (combined $\mathrm{N}$ and P) should be used. On the other hand, if an existing facility needs to be optimized by means of mathematical modelling and a selection of control strategies or operational procedures then combined ASM1, 2d reactive settler + decay or ASM3 would be more appropriate. Indeed, the latter ones include additional processes and it is possible to create a better picture of how the plant will behave taking into account the existing multiple interactions.

It is essential for everyone working with modelling and simulation of WWTPs to be fully aware of the dramatically different results that can be obtained due to the choice of model and model structure. The set of models investigated in this paper, i.e. ASM1, 2d and 3, reactive or non-reactive settler model, electron-acceptor dependent decay rates or not, all fall within the similar category of models and still the results vary significantly. Most model users will probably not give much thought about which model structure to use and simply assume all these well-established models to produce similar results. Thereby simulation results may easily be misinterpreted and conclusions misleading, simply because many users are not aware of how much the initial choice of model will influence the outcome of a simulation study 


\section{CONCLUSIONS}

The key findings are summarized in the following points:

1 - Mathematical model structure - and as a consequence the model assumptions made when creating a WWTP model - has a strong influence on the simulated overall BNR performance;

2 - Reactive settler 1) increases the hydrolysis of particulates; 2) reduces $S_{\mathrm{NO}}$ concentration (bottom); 3) increases the oxidation of COD compounds and $S_{\mathrm{NH}}$ (top); 4) increases $X_{\mathrm{H}}$ and $X_{\mathrm{A}}$ decay; and, finally 5) increases the growth of $X_{\mathrm{PAO}}$ and formation of $X_{\mathrm{PHA}}$ for ASM2d;

3 - The electron-acceptor dependent decay modification substantially increases the concentration of $X_{\mathrm{A}}, X_{\mathrm{B}}$ and $X_{\mathrm{PAO}}$;

4 - The death-regeneration concept has a significant influence on biomass behaviour in ASM1 and ASM2d.

\section{REFERENCES}

Comas J., Rodríguez-Roda I., Gernaey K.V., Rosen C., Jeppsson U. and Poch M. (2008). Risk assessment modelling of microbiology-related solids separation problems in activated sludge systems. Env. Model. Softw., 23, (10-11), 12501261.

Copp J.B. (ed.) (2002). The COST Simulation Benchmark: Description and Simulator Manual. ISBN 92-894-1658-0, Office for Official Publications of the European Community, Luxembourg.

Copp J.B. and Spanjers H. (2004). Simulation of respirometry-based detection and mitigation of activated sludge toxicity. Control Eng. Pract., 12, (3), 305-313.

Flores X., Poch M., Rodríguez-Roda I., Bañares-Alcántara R. and Jiménez L. (2007). Systematic procedure to handle critical decisions during the conceptual design of activated sludge systems. Ind. Eng. Chem. Res., 46, (17), 5600-5613.

Flores-Alsina X., Comas J., Rodriguez-Roda I., Gernaey K.V. and Rosen C (2009). Including the effects of filamentous bulking sludge during the simulation of wastewater treatment plants using a risk assessment model. Wat. Res., 43, (18), 4527-4538.

Gernaey K.V. and Jørgensen S.B. (2004). Benchmarking combined biological phosphorus and nitrogen removal wastewater treatment processes. Control Eng. Pract., 12,(3), 357-373.

Gernaey K.V., Flores-Alsina X., Rosen C., Benededtti L. and Jeppsson U. (2011). Phenomenological modelling approach to generate WWTP disturbance scenarios. Submitted to Env. Model. Softw

Henze M., Gujer W., Mino T. and van Loosdrecht M.C.M. (2000). Activated Sludge Models ASM1, ASM2, ASM2d and ASM3. IWA Scientific and Technical Report No. 9, IWA Publishing, London, UK.

Hiatt W.C. and Grady C.P.L.Jr. (2008). An updated process model for carbon oxidation, nitrification, and denitrification. Water Environ. Res., 80, 2145-2156.

Hug T., Benedetti L., Hall E.R., Johnson B.R., Morgenroth E., Nopens I., Rieger L., Shaw A. and Vanrolleghem P.A. (2009). Wastewater treatment models in teaching and training: the mismatch between education and requirements for jobs. Wat. Sci. Tech., 59, (4), 745-753.

Jeppsson U., Pons M.N., Nopens I., Alex J., Copp J.B., Gernaey K.V., Rosen C., Steyer J.P. and Vanrolleghem. P.A. (2007). Benchmark Simulation Model No 2 - general protocol and exploratory case studies. Wat. Sci. Tech., 56, (8), 287-295.

Nopens I., Benedetti L., Jeppsson U., Pons M.-N., Alex J., Copp J.B., Gernaey K.V., Rosen C., Steyer J.-P. and Vanrolleghem P.A. (2010). Benchmark simulation model No 2: Finalisation of plant layout and default control strategy. Wat. Sci. Tech., 62, (9),1967-1974.

Rivas A., Irizar I. and Ayesa E. (2008). Model-based optimisation of Wastewater Treatment Plants design. Env. Model. Softw., 23, (4), 435-450.

Rodriguez-Roda I., Sànchez-Marrè M., Comas J., Baeza J., Colprim J., Lafuente J., Cortes U. and Poch M. (2002). A hybrid supervisory system to support WWTP operation: Implementation and validation. Wat. Sci. Tech., 45, (4-5), 289297.

Rosen C., Jeppsson U. and Vanrolleghem P.A. (2004). Towards a common benchmark for long-term process control and monitoring performance evaluation. Wat. Sci. Tech., 50,(11), 41-49.

Serralta J., Ferrer J., Borrás L. and Seco A. (2004). An extension of ASM2d including pH calculation. Wat. Res., 38, (19), 4029-4038.

Siegrist H., Brunner I., Koch G., Con Phan L. and Van Chieu L. (1999). Reduction of biomass decay under anoxic and anaerobic conditions. Wat. Sci Tech., 39, (1), 129-137.

Sin G., Kaelin D., Kampschreur M.J., Takács I., Wett B., Gernaey K.V., Rieger L., Siegrist H. and van Loosdrecht M.C.M. (2008). Modelling nitrite in wastewater treatment systems: A discussion of different modelling concepts. Wat. Sci. Tech., 58, (6), 1155-1171.

Takács I., Patry G.G. and Nolasco D. (1991). A dynamic model of the clarification-thickening process. Wat. Res., 25, (10), 1263-1271. 